\title{
Influence of Organic Acids on the Surface Composition of Sea Spray Aerosol
}

\author{
Isaak Unger, ${ }^{*, \dagger}$ Clara-Magdalena Saak, ${ }^{\dagger}$ Matthew Salter, ${ }^{\dagger, \boldsymbol{\Phi}, \dagger}$ Paul Zieger,,,$+ \boldsymbol{\Phi}$ \\ Minna Patanen, ${ }^{*, \S}$ and Olle Björneholm ${ }^{\dagger}$ \\ †Uppsala University, Box 516, SE-75120 Uppsala, Sweden \\ $\ddagger$ Department of Environmental Science and Analytical Chemistry, Stockholm University, \\ SE-10691 Stockholm, Sweden \\ IBolin Centre for Climate Research, SE-10691 Stockholm, Sweden \\ $\S$ Nano and Molecular Systems research Unit, Faculty of Science, P.O.Box 8000, FI-90014 \\ University of Oulu, Finland
}

E-mail: isaak.unger@physics.uu.se; minna.patanen@oulu.fi

Phone: (+358) 294481326 (M.P.) 


\begin{abstract}
Recent studies on sea spray aerosol indicate an enrichment of $\mathrm{Ca}^{2+}$ in small particles, which are often thought to originate from the very surface of a water body when bubbles burst. One model to explain this observation is the formation of ion pairs between $\mathrm{Ca}^{2+}(\mathrm{aq})$ and surface-active organic species. In this study, we have used Xray photoelectron spectroscopy to probe aqueous salt solutions and artificial sea spray aerosol to study whether ion pairing in the liquid environment also affects the surface composition of dry aerosol. Carboxylic acids were added to the sample solutions to mimic some of the organic compounds present in natural seawater. Our results show that the formation of a core-shell structure governs the surface composition of the aerosol. The core-shell structure contrasts previous observations of the dry sea spray aerosol on substrates. As such, this may indicate that substrates can impact the morphology of the dried aerosol.
\end{abstract}




\section{Introduction}

Oceans are an important natural source of aerosol particles often referred to as sea spray aerosol. These particles are generated when the action of wind on the ocean surface creates waves that break and entrain air bubbles that subsequently burst. ${ }^{1}$ An important characteristic of the sea spray aerosol is its complex and size-dependent chemical composition since the particles contain both inorganic salts and organic species in varying proportions. ${ }^{2-5}$ Sea spray aerosols play a significant role in the earth's radiation budget ${ }^{6}$ because they scatter solar radiation and act as cloud condensation nuclei. ${ }^{7}$ Their efficiency to act as condensation nuclei hinges on their hygroscopicity, ${ }^{8}$ which, in turn, depends on the size and composition of the particle surface. The bulk composition of sea spray aerosols depends on the particle diameter. While small particles tend to be dominated by organic compounds the smaller they are ${ }^{3,9}$ larger particles are composed of a wider variety of solutes and may contain whole organisms. ${ }^{10}$ After drying, large aerosol particles usually exhibit a heterogeneous internal structure with different crystallites. ${ }^{3,11-13}$

The investigation on the chemical composition of aerosol particle surfaces is notoriously difficult since many methods lack either the necessary nanometer resolution to probe the particle surface or adequate chemical sensitivity. For example, infrared (IR) spectroscopy spectroscopy probes molecular species present in a nanoparticle but usually lacks spatial resolution. Electron microscopy combined with electron energy loss spectroscopy (EELS) or energy dispersive X-ray (EDX) spectroscopy offers high spatial resolution and some information about the chemical composition of particles. ${ }^{12}$ Scanning transmission X-ray microscopy $(\mathrm{STXM})^{3,14}$ and ion scattering combined with secondary ion mass spectrometry ${ }^{15}$ are able to deliver detailed information about the chemical composition with a moderate spatial resolution. All of these approaches require the aerosol particles to be captured on a substrate, and, in some cases, particles are exposed to vacuum for an extended period, which may introduce measurement artifacts. Recent efforts to circumvent these problems by applying cryo-transmission electron microscopy (cryo-TEM) to aerosol particles have yielded 
promising results and conserved even soft internal structures of organic origin under vacuum conditions. ${ }^{10}$ Another common approach that avoids potential substrate effects involves suspending particles in an electrodynamic balance (EDB). This technique allows a single aerosol particle to be caught and investigated by various other methods, e.g., Raman spectroscopy in addition to the information obtained from the EDB. ${ }^{16}$ Large numbers of free-flying aerosol particles can be studied using laser ablation combined with time-of-flight ion spectrometry. This method has chemical sensitivity and is capable of depth profiling but it suffers from the 'matrix effect', which reduces the ion signal from organic components in the presence of alkali metals. ${ }^{17,18}$ Woods et al. have demonstrated another approach where wet aerosol particles were tagged with a probe molecule, which was subsequently photoionized. The authors were able to indirectly extract chemical and morphological information about the particles. ${ }^{19}$ One technique that exhibits both high spatial resolution and high chemical sensitivity is X-ray photoelectron spectroscopy (XPS) that we have utilized in this study. The depth sensitivity of the technique hinges on the kinetic energy of the emitted electrons, which also correlates with the chemical environment of probed atomic species. ${ }^{20}$ The feasibility of XPS to probe salt aerosol samples has been demonstrated by Antonsson et al. ${ }^{21}$ X-ray photoelectron (XP) spectra represent an average over thousands of individual particles. Due to the limited, kinetic energy-dependent probing depth of the technique, XPS is also very surface sensitive. We estimate the probing depth in the experiments presented here to be about $\sim 2 \mathrm{~nm}$ based on data available for solid-state samples. ${ }^{20}$ In comparison to e.g. EDX, which also provides high spatial resolution and elemental information, XPS can distinguish between different chemical environments of atoms through the chemical shift in electron binding energies. In this study, we have investigated samples that are more closely related to the chemical composition of sea spray aerosol than those studied by Antonsson et al. ${ }^{21}$ We produced sea spray aerosols by nebulizing an artificial sea salt solution and spiking the same solution with acetic acid. From the XP spectra we were able to deduce which ions and molecules are present within the top $\sim 2 \mathrm{~nm}$ of the dry sea spray aerosol. The artificial sea salt we 
used in our experiment contains a wide variety of salts, some of which are present at very low concentrations. We limit our discussion to chloride $\left(\mathrm{Cl}^{-}, 55 \%\right.$ mass faction), sodium $\left(\mathrm{Na}^{+}, 31 \%\right.$ mass fraction), sulfate $\left(\mathrm{SO}_{4}^{2-}, 8 \%\right.$ mass fraction), and calcium $\left(\mathrm{Ca}^{2+}, 1 \%\right.$ mass fraction). We find that the abundance of ions on the particle surface strongly depends on the organic and inorganic contents of the starting solution.

\section{Experimental Section}

We discuss data originating from experiments conducted with liquids and dried aerosol particles at two different synchrotron facilities using different experimental setups. Our measurements on aerosol particles were conducted at the PLÉIADES beamline at the synchrotron light source SOLEIL (Paris, France). Here, particles were produced from a parent solution, which was fed into an atomizer ( $\mathrm{N}^{\circ} 3076$, TSI Inc.) and guided through a diffusion drier filled with silica gel. The relative humidity was kept constant at $3 \% \mathrm{RH}$ and was monitored downstream of the diffusion drier during the experiment. The particle-laden gas stream was then directed into the experimental chamber through an aerodynamic lens, resulting in an aerosol beam. This beam intersected with the monochromatic X-ray beam from the beamline in front of a Scienta Omicron R-4000 hemispherical electron analyzer with a wide-angle lens. A sketch of the setup is shown in figure 1 a). The exit slit of the monochromator was kept at $300 \mu \mathrm{m}$ and the electron analyzer was operated at $200 \mathrm{eV}$ pass energy with a curved, $0.8 \mathrm{~mm}$ wide entrance slit. The respective total experimental resolution at the used photon energies was $420 \mathrm{meV}$ at $\hbar \omega=135 \mathrm{eV}(\mathrm{Na} 2 \mathrm{~s}), 550 \mathrm{meV}$ at $\hbar \omega=273 \mathrm{eV}(\mathrm{Cl} 2 \mathrm{p}), 640 \mathrm{meV}$ at $\hbar \omega=360 \mathrm{eV}(\mathrm{C} 1 \mathrm{~s})$ and $830 \mathrm{meV}$ at $\hbar \omega=424 \mathrm{eV}(\mathrm{Ca} 2 \mathrm{p})$. Further, technical details of the setup are provided in ref. 22 .

We recorded electron spectra from the $\mathrm{Na} 2 \mathrm{~s}, \mathrm{Ca} 2 \mathrm{p}, \mathrm{Cl} 2 \mathrm{p}$ and $\mathrm{C} 1 \mathrm{~s}$ levels with short acquisition time in quick succession and repeated this process several times in order to account 
for sudden changes of the experimental conditions. Data was only considered for analysis when conditions were stable during the measurement of the whole set of the aforementioned spectra. The stability was monitored with a Faraday cup (particle beam) and a photo diode (X-ray beam) behind the intersection region of the X-rays and the aerosol beam. Photon energies were chosen to produce photoelectrons with $70 \mathrm{eV}$ kinetic energy in order to maximize the surface sensitivity of our experiments. Data on the mean free path of electrons from aerosol particles in this energy range are sparse but we estimate the probing depths of our experiments to be $\sim 2 \mathrm{~nm} .{ }^{23-28}$

We determined the electromobility diameter of the dry aerosol particles with a scanning mobility particle sizer (SMPS) consisting of a differential mobility analyser model 3081 equipped with an X-ray neutraliser 3088, and water-based condensation particle counter 3786 by TSI Inc. The average diameter of the dry aerosol particles was $\sim 120 \mathrm{~nm}$ (main mode of a lognormal size distribution).

Our experiments on liquids took place at the $\mathrm{SOL}^{3}$ endstation ${ }^{29}$ at the U49/2 PGM1 beamline $^{30}$ at the synchrotron light source BESSY II (Berlin, Germany). We used a high performance liquid chromatography (HPLC) pump to inject the sample solutions from a sample reservoir through a quartz glass nozzle into vacuum. The liquid is in direct contact with a grounded gold wire a few centimeters upstream of the nozzle. The nozzle opening was about $20 \mu \mathrm{m}$ in diameter. The flow of the liquid $\sim 5 \mathrm{~mm}$ downstream of the nozzle is laminar before the jet breaks up into droplets, which subsequently freeze due to evaporative cooling. Our XPS measurements have been conducted on the region of laminar flow about $2 \mathrm{~mm}$ downstream of the glass nozzle.

The liquid jet and the X-rays intersect at an angle of $90^{\circ}$ in front of the $0.5 \mathrm{~mm}$ wide opening to a Scienta Omicron R4000 HIPP-2 hemispherical electron analyzer. This type of analyzer features two differential pumping sections to reduce the gas load on the multichannel plate of the detection unit.

In order to reduce the vapor pressure of the liquid, the sample solution is cooled to $4{ }^{\circ} \mathrm{C}$ 
a)

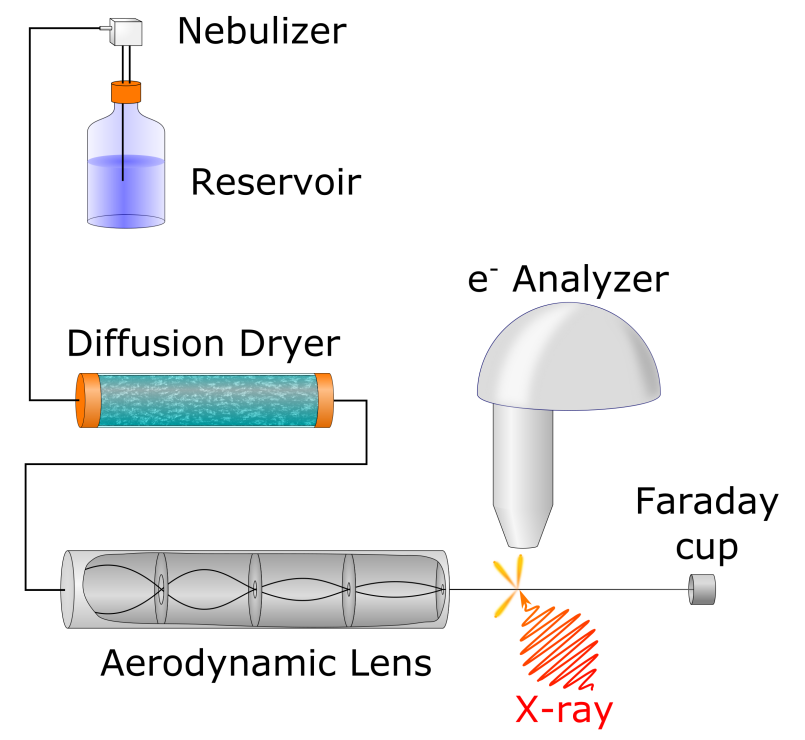

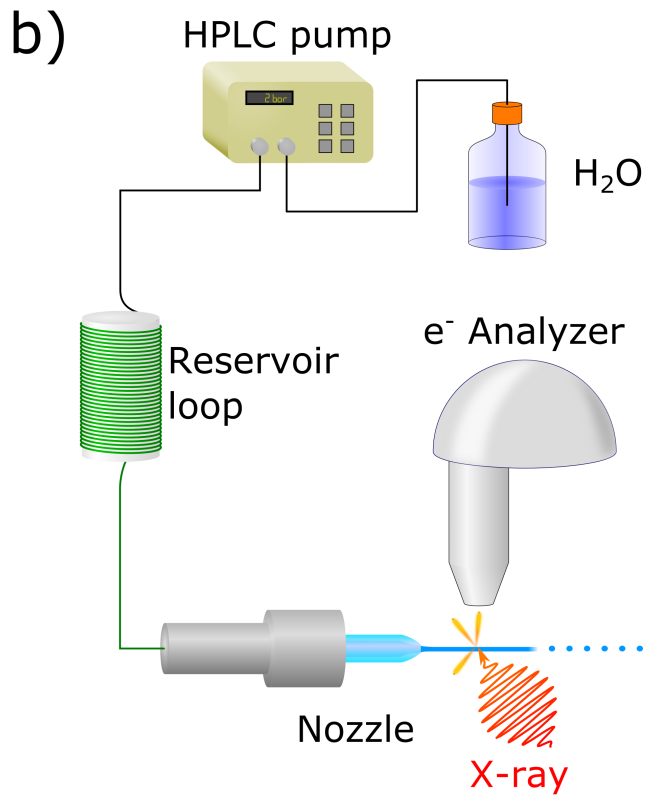

Figure 1: Authors have used two different setups to conduct the experiments. (a) Schemes of the setup for XPS on dry aerosols. First, aerosols are generated by a nebulizer from a solution. The aerosols are guided through a diffusion dryer and enter the aerodynamic lens through a flow-limiting orifice. The aerosol stream is focused into a tight beam in the aerodynamic lens and hit by X-rays in front of the electron analyzer. (b) Scheme of the liquid jet setup. An high-performance liquid chromatography (HPLC) pump forces the sample solution from a reservoir loop through a quartz glass nozzle, which results in the formation of a fast-flowing liquid jet. The liquid is hit by X-rays in front of the entrance to the electron analyzer before the liquid jet breaks up into droplets and freezes.

before entering the vacuum chamber. Used sample solution is caught on a cryo surface at liquid nitrogen temperature. An additional cooling trap and a turbomolecular pump keep the pressure in the vacuum chamber between $5 \cdot 10^{-4}$ mbar and $3 \cdot 10^{-3}$ mbar during operation. In order to prevent a high gas load on the beamline optics, the X-rays enter the experimental chamber through a differential pumping stage. The differential pumping stage features three pinholes, which separate differential pumping sections, each equipped with a cooling trap and a turbomolecular pump.

Solutions were prepared with salt provided by Sigma Aldrich (ACS reagent grade) and destilled water (specific resistance of $18.2 \mathrm{M} \Omega \mathrm{cm}$ ). The composition of the $35 \mathrm{~g} / 1$ sea salt solution is given in table 1 in the supporting information. In the following, we will refer 
to $35 \mathrm{~g} / \mathrm{l}(\sim 1 \mathrm{M})$ sea salt solution simply as 'sea salt solution' and separately name other compounds which have been added.

\section{Results}

Spectra from aerosols originating from different parent solutions are shown in figure 2. Each row depicts spectra of particles from a different parent solution and its composition is given below the respective row. Spectra of a given atomic level from different aerosol compositions are depicted in the individual columns of the figure.

Composition-dependent changes appear in the spectra of $\mathrm{Na} 2 \mathrm{~s}$ and $\mathrm{Ca} 2 \mathrm{p}$ as depicted in the first two columns. The $\mathrm{Na} 2 \mathrm{~s}$ line is situated at $\sim 68 \mathrm{eV}$ binding energy and the $\mathrm{Ca}$ $2 \mathrm{p}$ doublet appears at $\sim 349 \mathrm{eV}$ and $\sim 350 \mathrm{eV}$ binding energy, respectively. We measured aerosol particles from a mixture of $0.1 \mathrm{M} \mathrm{NaCl}+0.1 \mathrm{M} \mathrm{CaCl} \mathrm{Cl}_{2}$ and $0.08 \mathrm{M} \mathrm{NaCl}+0.02 \mathrm{M}$ $\mathrm{CaCl}_{2}$ for comparison (figure $2 \mathrm{a}, \mathrm{b}$ ). Here, only the $\mathrm{Ca} 2 \mathrm{p}$ levels were observable. This changes for particles generated from the artificial sea salt solution (figure 2c) where the Ca $2 \mathrm{p}$ signal disappears and the $\mathrm{Na} 2 \mathrm{~s}$ photoelectron line is clearly visible. The trend reverses again upon adding excess $\mathrm{CaCl}_{2}$ to the artificial sea salt solution, and the $\mathrm{Ca} 2 \mathrm{p}$ peaks reappear, while the $\mathrm{Na} 2 \mathrm{~s}$ peak vanishes (see figure 2d). Adding $0.62 \mathrm{~g} / 1(0.01 \mathrm{M})$ acetic acid to the parent solution with added $\mathrm{CaCl}_{2}$ leads to a re-appearance of the sodium peak and the disappearance of the $\mathrm{Ca} 2 \mathrm{p}$ peaks. Adding more acetic acid to the solution does not lead to further changes in the observed spectra. The $\mathrm{Cl} 2 \mathrm{p}$ levels are clearly observable and quite similar for most solutions. On close inspection of the $\mathrm{Cl} 2 \mathrm{p}$ spectrum from $0.1 \mathrm{M} \mathrm{NaCl}$ $+0.1 \mathrm{M} \mathrm{CaCl}_{2}$ solution a $\sim 0.1 \mathrm{eV}$ shift to lower binding energies becomes apparent (see figure 2 a)). This is most likely due to a slight shift in the excitation energy. C 1s levels have been recorded to monitor the acetic acid on the surface of the aerosol particles. In the C 1s region a well-pronounced carbon peak at $\sim 289 \mathrm{eV}$ binding energy is observable for an artificial sea salt solution with additional $\mathrm{CaCl}_{2}$ even though no organic compound was 


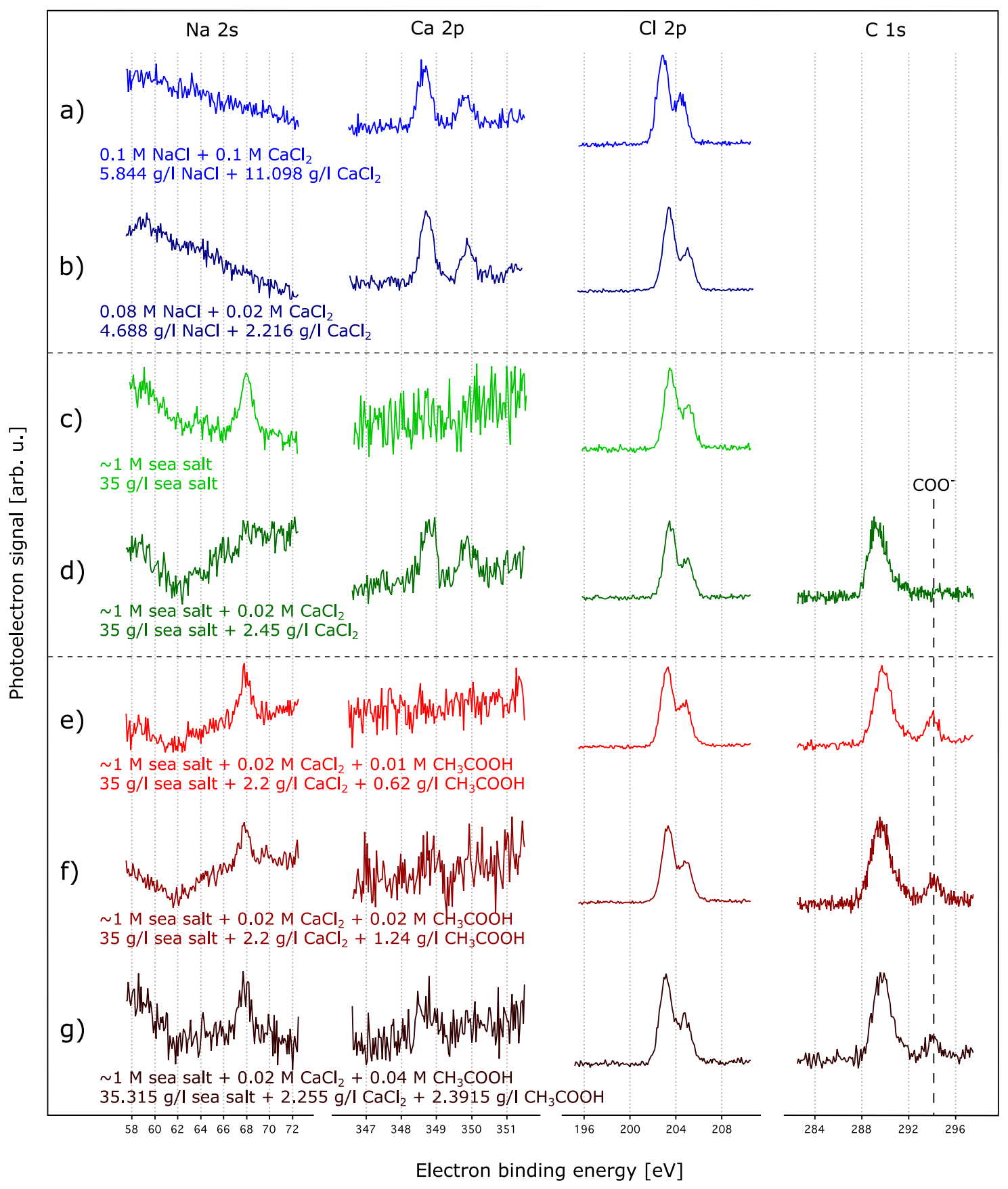

Figure 2: $\mathrm{Na} 2 \mathrm{~s}, \mathrm{Ca} 2 \mathrm{p}, \mathrm{Cl} 2 \mathrm{p}$ and $\mathrm{C}$ 1s photoelectron spectra obtained from dried aerosol particles originating from different parent solutions with concentrations a) $0.1 \mathrm{M} \mathrm{NaCl}+$ $0.1 \mathrm{M} \mathrm{CaCl}_{2}$ b) $0.08 \mathrm{M} \mathrm{NaCl}+0.02 \mathrm{M} \mathrm{CaCl}_{2}$ c) $1 \mathrm{M}$ sea salt d) $1 \mathrm{M}$ sea salt $+0.02 \mathrm{M} \mathrm{CaCl}_{2}$ e) $1 \mathrm{M}$ sea salt $+0.02 \mathrm{M} \mathrm{CaCl}_{2}+0.01 \mathrm{M} \mathrm{CH}_{3} \mathrm{COOH}$ f) $1 \mathrm{M}$ sea salt $+0.02 \mathrm{M} \mathrm{CaCl}_{2}+$ $0.02 \mathrm{M} \mathrm{CH}_{3} \mathrm{COOH}$ g) $1 \mathrm{M}+0.02 \mathrm{M} \mathrm{CaCl}_{2}+0.04 \mathrm{M} \mathrm{CH}_{3} \mathrm{COOH}$. Spectra are also labeled correspondingly using the $\mathrm{g} / \mathrm{l}$ units. 
added to the solution (figure 2d)). The excess carbon signal is observable in the $\mathrm{C}$ 1s spectra from the other solutions as well, and we attribute this peak to physisorbed organic carbon picked up by the particles from the carbon-coated silicone tubing used in the experiments or to impurities in the carrier gas used to run the nebulizer. Contamination stemming from the use of such tubing has been reported previously. ${ }^{31,32}$

The observed spectra from the XPS experiment on a liquid jet are presented in figure 3 . Due to the relatively low amount of $\mathrm{Ca}^{2+}$ in the artificial sea salt solution we chose to use a sample solution containing $0.1 \mathrm{M} \mathrm{NaCl}+0.1 \mathrm{M} \mathrm{CaCl}_{2}$ in these experiments, which produces sufficiently high Ca $2 \mathrm{p}$ signal intensity. In contrast to the results from aerosol particles, carbon was only observed when organic compound was added to the solution.

We observe a similar picture in all solutions: The Na 2 s level can hardly be discerned, whereas the $\mathrm{Ca} 2 \mathrm{p}$ peaks are clearly visible, no matter if varying amounts of acetic acid, hexanoic acid or octanoic acid are added to the solution. The carbon region only shows the contribution of the added organic acid.

\section{Discussion}

Studies by Cochran et al. ${ }^{33}$ and by Salter et al. ${ }^{34}$ are the backdrop for our experiments. The latter study found an increased concentration of $\mathrm{Ca}^{2+}$ ions in small aerosol particles in com-

parison to larger particles and to the solution from which the aerosol was generated. ${ }^{34}$ All particles in these experiments were generated through bubble bursting and the small particles are considered to be film droplets, which originate from the water surface. Cochran et al. studied selective transfer of a certain organic compounds from sea salt solution spiked with linear carboxylates and dicarboxylates into the aerosol phase. Based on their observations and vast literature in organic-inorganic interactions at air-water interface, they proposed that inorganic ions engage in a strong interaction with the carboxylate group of carboxylic acids, which are enriched at the surface of a solution. ${ }^{33}$ The question arising from these two 


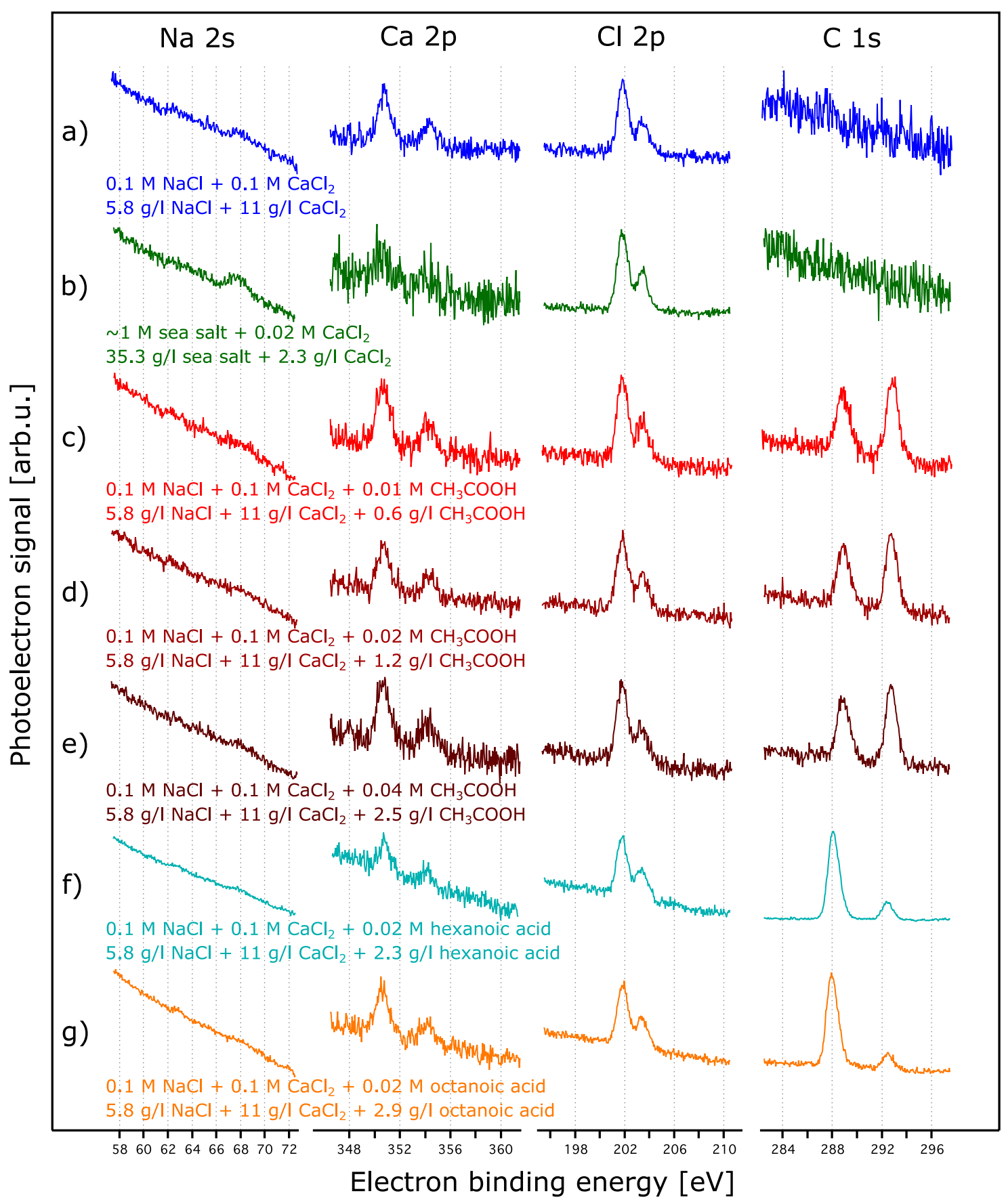

Figure 3: The photoelectron spectra of the liquid jet experiment. Compositions of aqueous solutions are a) $0.1 \mathrm{M} \mathrm{NaCl}+0.1 \mathrm{M} \mathrm{CaCl}_{2}$ b) $1 \mathrm{M}$ sea salt $+0.02 \mathrm{M} \mathrm{CaCl}_{2}$ c) $0.1 \mathrm{M} \mathrm{NaCl}$ $+0.1 \mathrm{M} \mathrm{CaCl}_{2}+0.01 \mathrm{M} \mathrm{CH}_{3} \mathrm{COOH}$ d) $0.1 \mathrm{M} \mathrm{NaCl}+0.1 \mathrm{M} \mathrm{CaCl}_{2}+0.02 \mathrm{M} \mathrm{CH}_{3} \mathrm{COOH}$ e) $0.1 \mathrm{M} \mathrm{NaCl}+0.1 \mathrm{M} \mathrm{CaCl}_{2}+0.04 \mathrm{M} \mathrm{CH}_{3} \mathrm{COOH}$ f) $0.1 \mathrm{M} \mathrm{NaCl}+0.1 \mathrm{M} \mathrm{CaCl}_{2}+0.02 \mathrm{M}$ $\mathrm{CH}_{3}\left(\mathrm{CH}_{2}\right)_{4} \mathrm{COOH}$ g) $0.1 \mathrm{M} \mathrm{NaCl}+0.1 \mathrm{M} \mathrm{CaCl}_{2}+0.02 \mathrm{M} \mathrm{CH}_{3}\left(\mathrm{CH}_{2}\right)_{6} \mathrm{COOH}$. Spectra are also labeled correspondingly using the g/l units. The columns of the figure show spectra of different atomic species and the rows all spectra from one specific solution. 
studies is whether the interaction between $\mathrm{Ca}^{2+}(\mathrm{aq})$ and carboxylic acids translates into an increased surface concentration of $\mathrm{Ca}^{2+}$ in dry aerosol particles if the carboxylic acid is also present at the surface of the particles.

In order to obtain a more complete picture of the processes involved in the enrichment of ions in dry aerosol, we first conducted our experiments on the most simple system: Aerosol from a binary mixture of $\mathrm{NaCl}$ and $\mathrm{CaCl}_{2}$ (figure 2a,b). Taking into account the photoionization cross-sections $^{35,36}$ and the photon flux of the beamline, a Na-to-Ca ratio of 0.9 would be expected when equal amounts of $\mathrm{Na}^{+}$and $\mathrm{Ca}^{2+}$ are present in the solution. Yet no sodium can be observed at the surface of the aerosol particles. The surface of the particles contains only $\mathrm{CaCl}_{2}$. Increasing the amount of $\mathrm{Na}^{+}$(aq) by a factor of four relative to the amount of $\mathrm{Ca}^{2+}(\mathrm{aq})$ in the parent solution yields a similar result: the surface layer of the dry particles contains only $\mathrm{CaCl}_{2}$. This can be explained by the drying process of the aerosol particles in which a core of $\mathrm{NaCl}$ crystallizes first and at lower relative humidity a shell of $\mathrm{CaCl}_{2}$ forms around it.

We underline the notion of a core-shell structure in our experiments. Images of aerosol obtained by microscopy usually show different salt crystals next to one another, not a coreshell structure (see e.g. microscopy images of aerosols in references 3,13). In our experiment, the orientation of the aerosol particles with respect to the light source and the detector is random. If $\mathrm{NaCl}$ and $\mathrm{CaCl}_{2}$ crystals would form side to side during the drying process, we would observe spectral features of both ions. Since this is not the case, we assume that all the $\mathrm{NaCl}$ is completely covered by $\mathrm{CaCl}_{2}$ in the majority of the dry particles.

In order to obtain information about the presence of $\mathrm{Na}^{+}(\mathrm{aq})$ and $\mathrm{Ca}^{2+}(\mathrm{aq})$ before the drying process, we investigated a 1:1 mixture of $\mathrm{NaCl}$ and $\mathrm{CaCl}_{2}$ with XPS on a liquid jet (see figure $3 \mathrm{a})$ ). In the liquid phase, the $\mathrm{Ca} 2 \mathrm{p}$ lines are clearly visible, whereas the $\mathrm{Na} 2 \mathrm{~s}$ line cannot be clearly discerned above the noise background. Considering the photoionization cross sections of the Na 2s level and the Ca 2p level at 135 and 424 eV photon energy, respectively, and the photon flux of the beamline at these energies, one would expect about 
1.3 times more signal from $\mathrm{Na} 2 \mathrm{~s}$ than from Ca 2p. ${ }^{30,35,36}$ Accordingly, we interpret the lack of $\mathrm{Na}$ 2s signal as a surface depletion of $\mathrm{Na}^{+}(\mathrm{aq})$ in comparison to $\mathrm{Ca}^{2+}(\mathrm{aq})$ in the liquid phase.

XP spectra from a sea salt solution (figure 3b)) show both, the Na 2 s and the Ca 2p levels, however the signal to noise ratio in the Ca $2 \mathrm{p}$ region is poor, probably due to the low concentration of $\mathrm{Ca}^{2+}(\mathrm{aq})$ (about $0.0092 \mathrm{M}$ ). This is an indication that $\mathrm{Na}^{+}(\mathrm{aq})$ and $\mathrm{Ca}^{2+}(\mathrm{aq})$ are present at the surface of a sea salt solution before drying. The results from the dry aerosol particles originating from a sea salt solution show only the $\mathrm{Na} 2 \mathrm{~s}$ peak (see figure $2 \mathrm{c}$ ). The absence of the $\mathrm{Ca} 2 \mathrm{p}$ signal and the presence of $\mathrm{Na}^{+}$at the particle surface is in stark contrast to the observations on dry aerosol from binary solutions containing only $\mathrm{NaCl}$ and $\mathrm{CaCl}_{2}$ (compare to figure 2a,b). Moreover, this result implies that all the calcium in the dry aerosol particles is now covered below a layer of sodium salt. This observation is in line with results from Raman spectroscopy by Xiao et al., indicating that the first salt to crystallize upon decreasing the relative humidity is $\mathrm{CaSO}_{4} \cdot 0.5 \mathrm{H}_{2} \mathrm{O} .{ }^{11}$ According to this study, $\mathrm{NaCl}$ crystallizes after $\mathrm{CaSO}_{4} \cdot 0.5 \mathrm{H}_{2} \mathrm{O}$ at lower relative humidity. Therefore, we propose that our dried aerosol particles from a sea salt solution are composed of a core containing $\mathrm{Ca}^{2+}$ and $\mathrm{SO}_{4}^{2-}$ covered by a $\mathrm{NaCl}$ shell. This is remarkable as most microscopy studies do not find a core-shell structure in dried sea spray aerosol but rather crystals of $\mathrm{NaCl}$ and $\mathrm{CaSO}_{4}$ separate from one another. Considering that most microscopy studies collect wet aerosol on a substrate and dry them before investigation, we speculate that our divergent observations might be due to the absence of a substrate during the drying process.

We continue the discussion with results from dry aerosol generated from a solution containing $35 \mathrm{~g} / 1$ sea salt with added $\mathrm{CaCl}_{2}$; the respective XP spectra are shown in figure $2 \mathrm{~d}$ ). In comparison with aerosol generated from a sea salt solution with no added $\mathrm{CaCl}_{2}$ (figure 2c), the sodium signal vanished here and the Ca $2 \mathrm{p}$ lines are clearly visible. Therefore, we believe that now all available $\mathrm{Na}^{+}$is covered by a layer of calcium salt. We can rationalize this result by considering the concentration of $\mathrm{Ca}^{2+}(\mathrm{aq})$ and $\mathrm{SO}_{4}^{2-}(\mathrm{aq})$ in the pure sea 
salt solution. The concentration of $\mathrm{SO}_{4}^{2-}(\mathrm{aq})$ is $0.0255 \mathrm{M}$ and the $\mathrm{Ca}^{2+}$ (aq) concentration is about $0.0092 \mathrm{M}$ in pure sea salt solution and $0.0292 \mathrm{M}$ in sea salt solution with added $\mathrm{CaCl}_{2}$, respectively. Let us consider aerosol from a pure sea salt solution first. The concentration of $\mathrm{SO}_{4}^{2-}(\mathrm{aq})$ exceeds the one of $\mathrm{Ca}^{2+}(\mathrm{aq})$. During the drying process of the aerosol, a core containing $\mathrm{Ca}^{2+}$ and $\mathrm{SO}_{4}^{2-}$ forms initially. This process uses up all the available calcium in the droplet. The core is subsequently covered by a shell of $\mathrm{NaCl}$ and we only observe $\mathrm{Na}^{+}$ at the surface of aerosol generated from a pure sea salt solution.

The solution containing sea salt with added $\mathrm{CaCl}_{2}$ contains more $\mathrm{Ca}^{2+}(\mathrm{aq})$ than $\mathrm{SO}_{4}^{2-}(\mathrm{aq})$ and after the formation of the core, an excess of $\mathrm{Ca}^{2+}$ is left over. The leftover $\mathrm{Ca}^{2+}$ forms a second shell around the $\mathrm{NaCl}$ layer, most probably $\mathrm{CaCl}_{2}$ and thus we observe only $\mathrm{Ca}^{2+}$ at the aerosol surface and no $\mathrm{Na}^{+}$.

In summary, our experiments with pure salts highlight that an excess of $\mathrm{Ca}^{2+}(\mathrm{aq})$ at the surface of a solution of inorganic salts does not necessarily translate into a surface enrichment at the surface of dry aerosol particles. As expected, the surface composition of the particles is rather determined by the efflorescence points of the inorganic salts they contain. Given this, we know turn to the discussion of our results from inorganic salt solutions with added organic acids.

We begin with our liquid jet data using a $0.1 \mathrm{M} \mathrm{NaCl}+0.1 \mathrm{M} \mathrm{CaCl}_{2}$ solution spiked with varying concentrations of acetic acid, hexanoic acid and octanoic acid, which are depicted in figures $3 \mathrm{c}-\mathrm{g}$ ), respectively. The only obvious difference in the spectra occurs in the carbon region, which reflects the concentration and kind of organic acid added to the solution. While the $\mathrm{Ca} 2 \mathrm{p}$ peaks are visible, the $\mathrm{Na} 2 \mathrm{~s}$ peak is not. This implies that the surface of the solution is composed of mostly $\mathrm{Ca}^{2+}(\mathrm{aq})$ ions which is in accordance with results from vibrational sum frequency generation spectroscopy, ${ }^{37}$ which found that $\mathrm{Ca}^{2+}(\mathrm{aq})$ strongly interacts with carboxylate groups.

$\mathrm{XP}$ spectra from dry aerosol generated from a sea salt solution with additional $\mathrm{CaCl}_{2}$ and varying amounts of acetic acid are shown in figure 2e-g). Independent of the amount of 
acetic acid we added, only the sodium peak could be observed in these spectra and the Ca $2 \mathrm{p}$ signal was absent. As we described previously, $\mathrm{Ca}^{2+}(\mathrm{aq})$ is enriched at the surface of a liquid. Assuming that this also holds true for the surface of liquid aerosol particles prior to drying, and the fact that we observe acetic acid at the surface of the dry particles, one could expect to find $\mathrm{Ca}^{2+}$ at the dry aerosol surface as well. Clearly, this is not the case and the surface enrichment of $\mathrm{Ca}^{2+}(\mathrm{aq})$ in an aqueous solution does not translate to a surface enrichment of $\mathrm{Ca}^{2+}$ in dry particles in the presence of acetic acid. Once again, these results imply the formation of aerosol particles with a core-shell structure during the drying process. As previously described, we expect that a core of $\mathrm{Ca}^{2+}$ and $\mathrm{SO}_{4}^{2-}$ forms initially. Here, the shell forming around the core may contain $\mathrm{NaCl}$ and $\mathrm{Ca}\left(\mathrm{CH}_{3} \mathrm{COO}\right)_{2}$ since both salts have a similar solubility in water. ${ }^{38,39}$ Since efflorescence data on co-solutions of $\mathrm{NaCl}$ and $\mathrm{Ca}\left(\mathrm{CH}_{3} \mathrm{COO}\right)_{2}$ is not available we can only speculate about the composition of that first shell based on our experimental results. The formation of the $\mathrm{NaCl} / \mathrm{Ca}\left(\mathrm{CH}_{3} \mathrm{COO}\right)_{2}$ shell uses up the available calcium left over after the formation of the particle core. Since the surface of the particles is covered with a layer $(<2 \mathrm{~nm}$ thick) containing acetate, chloride and sodium we are unable to detect any calcium signal from the surface of such aerosol particles. We have also attempted to derive quantitative data about the surface enrichment of $\mathrm{Na}^{+}$relative to $\mathrm{Cl}^{-}$from the XP spectra. To this end, we fitted the XPS peaks and normalized the peak areas by molarity of the ion, photon flux and photoionization cross section. However, the $\mathrm{Na}^{+} / \mathrm{Cl}^{-}$ratio as a function of the $\mathrm{CH}_{3} \mathrm{COOH}$ concentration in the parent solution is rather inconclusive due to the large error bars (see figure 1 in the supporting information). Although we did not observe any change in the ratio with increasing $\mathrm{CH}_{3} \mathrm{COOH}$ concentration we can see from the data that an increase of the $\mathrm{Na}^{+} / \mathrm{Cl}^{-}$ratio must take place below $0.01 \mathrm{M} \mathrm{CH}_{3} \mathrm{COOH}$ concentration.

Our results suggest that aerosol particles in free flight form a core-shell structure upon drying. The main driving forces for the formation of the core-shell structure are the efflorescence points of the constituents of the wet aerosol particle. This gives rise to a different structure 
of the dry sea spray aerosol as has been reported in studies in which aerosols have been deposited on a hygroscopic substrate prior to investigation. ${ }^{3,13}$ To draw a definitive conclusion about a possible substrate effect on the structure of dry aerosol and to reveal the underlying processes leading to the observed differences, a thorough investigation utilizing various complementary methods at once is necessary. In particular collocated sampling via free flight and substrate methods will be indispensable.

\section{Conclusions}

We have used XPS to probe dry aerosol particles produced from different solutions with an atomizer where we were able to detect $\mathrm{Ca}^{2+}, \mathrm{Na}^{+}, \mathrm{Cl}^{-}$and $\mathrm{CH}_{3} \mathrm{COO}^{-}$within the top $2 \mathrm{~nm}$ of the particles depending on the composition of the parent solution. These results have been complemented with XPS measurements on salt solutions mimicking those used for the aerosol generation. One of the questions we set out to explore with this work is whether the pairing between carboxylate groups and $\mathrm{Ca}^{2+}(\mathrm{aq})$ at the surface of a liquid aerosol droplet translates into the structure of dry aerosol particles. Our data implies that this is not the case. Instead, the efflorescence points of the salts determine the composition of the particle surfaces. In this regard our results are in line with measurements of aerosol droplets caught on grids. ${ }^{11,40}$

A difference between our results and many investigations of aerosol deposited on a substrate is the emergence of a core-shell structure of the dry particles in our experiments. This might be due to the influence of the substrate on which aerosol is deposited before drying. If that is the case, a series of dedicated experiments is necessary to determine the nature of the substrate effect. A first effort into this direction has been made by Eom et al., who found that hygroscopic substrates hardly influence the efflorescence points of deposited salt droplets. ${ }^{41}$ Since aerosol particles are usually collected on hydrophobic substrates, this underscores the necessity to dedicate more research to the aspect of the influence of substrates. 


\section{Supporting Information}

Supporting information contains descriptions of composition of the $35 \mathrm{~g} / \mathrm{l}$ sea salt solution, qualitative analysis of signal intensities, structure of dried sea spray aerosol.

\section{Acknowledgement}

The authors would like to thank Christophe Nicolas, Aleksandar Milosavljevic, John Bozek, and Ilona Riipinen for their support and thoughts surrounding this article and Edwin Kukk for the SPANCF curve-fitting package. M.P. acknowledges the support from the Academy of Finland. I.U. thanks Stephan Thürmer for some of the procedures for data analysis and the Carl Tryggers Foundation for financiall support. M. S. was financed by the Swedish Research Council (project number 2016-05100). P. Z. acknowledges funding from the Knut and Alice Wallenberg Foundation, project Arctic Climate Across Scales (ACAS; project no. 2016.0024). Parts of this research were carried out at PLEIADES beamline at SOLEIL synchrotron (proposal number 20160032). We would like to thank Dr. Christophe Nicolas for assistance during the experiment. We thank also HZB for the allocation synchrotron radiation beamtime.

\section{References}

(1) de Leeuw, G.; Neele, F. P.; Hill, M.; Smith, M. H.; Vignati, E. Production of sea spray aerosol in the surf zone. Journal of Geophysical Research: Atmosphere 2000, $105,29397-29409$.

(2) O’Dowd, C. D.; Facchini, M. C.; Cavalli, F.; Ceburnis, D.; Mircea, M.; Decesari, S.; Fuzzi, S.; Yoon, Y. J.; Putaud, J.-P. Biogenically driven organic contribution to marine aerosol. Nature 2004, 431, $676-680$. 
(3) Ault, A. P.; Moffet, R. C.; Baltrusaitis, J.; Collins, D. B.; Ruppel, M. J.; CuadraRodriguez, L. A.; Zhao, D.; Guasco, T. L.; Ebben, C. J.; Geiger, F. M. et al. SizeDependent Changes in Sea Spray Aerosol Composition and Properties with Different Seawater Conditions. Environmental Science and Technology 2013, 47, 5603-5612.

(4) Blanchard, D. C. Sea-to-air transport of surface active material. Science 1964, 146, $396-397$.

(5) Tseng, R.-S.; Viechnicki, J. T.; Skop, R. A.; Brown, J. W. Sea-to-air transfer of surfaceactive organic compounds by bursting bubbles. Journal of Geophysical Research 1992 , $97,5201-5206$.

(6) Jacobson, M. Z. Global direct radiative forcing due to multicomponent anthropogenic and natural aerosols. Journal of Geophysical Research: Atmospheres 2001, 106, 15511568.

(7) Quinn, P.; Coffman, D.; Johnson, J.; Upchurch, L.; Bates, T. Small fraction of marine cloud condensation nuclei made up of sea spray aerosol. Nature Geoscience 2017, 10, $674-679$.

(8) Zieger, P.; Väisänen, O.; Corbin, J.; Partridge, D. G.; Bastelberger, S.; MousaviFard, M.; Rosati, B.; Gysel, M.; Krieger, U.; Leck, C. et al. Revising the hygroscopicity of inorganic sea salt particles. Nature Communications 2017, 8 .

(9) Oppo, C.; Bellandi, S.; Innocenti, N. D.; Stortini, A.; Loglio, G.; Schiavuta, E.; Cini, R. Surfactant components of marine organic matter as agents for biogeochemical fractionation and pollutant transport via marine aerosols. Marine Chemistry 1999, 63, 235-253.

(10) Patterson, J. P.; Collins, D. B.; Michaud, J. M.; Axson, J. L.; Sultana, C. M.; Moser, T.; Dommer, A. C.; Conner, J.; Grassian, V. H.; Stokes, M. D. et al. Sea spray aerosol structure and composition using cryogenic transmission electron microscopy. ACS Central Science 2016, 2, $40-47$. 
(11) Xiao, H.-S.; Dong, J.-L.; Wang, L.-Y.; Zhao, L.-J.; Wang, F.; Zhang, Y.-H. Spatially resolved micro-Raman observation on the phase separation of effloresced sea salt droplets. Environ. Sci. Technol. 2008, 42, 8698-8702.

(12) Ault, A. P.; Guasco, T. L.; Ryder, O. S.; Baltrusaitis, J.; Cuadra-Rodriguez, L. A.; Collins, D. B.; Ruppel, M. J.; Bertram, T. H.; Prather, K. A.; Grassian, V. H. Inside versus Outside: Ion Redistribution in Nitric Acid Reacted Sea Spray Aerosol Particles as Determined by Single Particle Analysis. Journal of the American Chemical Society 2013, 135, 14528-14531.

(13) Chi, J.; Li, W. J.; Zhang, D. Z.; Zhang, J. C.; Lin, Y. T.; Shen, X. J.; Sun, J. Y.; Chen, J. M.; Zhang, X. Y.; Zhang, Y. M. et al. Sea salt aerosols as a reactive surface for inorganic and organic acidic gases in the Arctic troposphere. Atmospheric Chemistry and Physics 2015, 15, 11341-11353.

(14) Pham, D. Q.; O’Brien, R.; Fraund, M.; Bonanno, D.; Laskina, O.; Beall, C.; Moore, K. A.; Forestieri, S.; Wang, X.; Lee, C. et al. Biological Impacts on Carbon Speciation and Morphology of Sea Spray Aerosol. ACS Earth and Space Chemistry 2017, 1, 551-561.

(15) Sobanska, S.; Falgayrac, G.; Rimetz-Planchon, J.; Perdrix, E.; Brémard, C.; Barbillat, J. Resolving the internal structure of individual atmospheric aerosol particle by the combination of Atomic Force Microscopy, ESEM-EDX, Raman and ToF-SIMS imaging. Microchemical Journal 2014, 114, 89-98.

(16) Haddrell, A. E.; Davies, J. F.; Yabushita, A.; Reid, J. P. Accounting for Changes in Particle Charge, Dry Mass and Composition Occurring During Studies of Single Levitated Particles. The Journal of Physical Chemistry A 2012, 116, 9941-9953.

(17) Zelenyuk, A.; Yang, J.; Song, C.; Zaveri, R. A.; Imre, D. "Depth Profiling" and Quantitative Characterization of the Size, Composition, Shape, Density, and Morphology of 
Fine Particles with SPLAT, a Single-Particle Mass Spectrometer. Microchemical Journal 2008, 112, 669-677.

(18) Cai, Y.; Zelenyuk, A.; Imre, D. A High Resolution Study of the Effect of Morphology On the Mass Spectra of Single PSL Particles with Na-containing Layers and Nodules. Aerosol Science and Technology 2006, 40, 1111-1122.

(19) Woods, E.; Chung, D.; Lanney, H. M.; Ashwell, B. A. Surface Morphology and Phase Transitions in Mixed $\mathrm{NaCl} / \mathrm{MgSO}_{4}$ Aerosol Particles. The Journal of Physical Chemistry A 2010, 114, 2837-2844.

(20) Hüfner, S. Photoelectron Spectroscop; Springer-Verlag Berlin Heidelberg New York: Springer-Verlag GmbH, Tiergartenstrasse 17, D-69121 Heidelberg, Germany, 2003.

(21) Antonsson, E.; Patanen, M.; Nicolas, C.; Neville, J. J.; Benkoula, S.; Goel, A.; Miron, C. Complete bromide surface segregation in mixed $\mathrm{NaCl} / \mathrm{NaBr}$ aerosols grown from droplets. Phys. Rev. X 2015, 5, 011025.

(22) Lindblad, A.; Söderström, J.; Nicolas, C.; Robert, E.; Miron, C. A multi purpose source chamber at the PLEIADES beamline at SOLEIL for spectroscopic studies of isolated species: Cold molecules, clusters, and nanoparticles. Rev. Sci. Instrum. 2013, 84,113105 .

(23) Akkerman, A.; Boutboul, T.; Breskin, A.; Chechik, R.; Gibrekhterman, A. Low-energy electron transport in alkali halides. J. Appl. Phys. 1994, 76, 4656-4662.

(24) Signorell, R.; Goldmann, M.; Yoder, B. L.; Bodi, A.; Chasovskikh, E.; Lang, L.; Luckhaus, D. Nanofocussing, shadowing, and electron mean free path in the photoemission from aerosol droplets. Chem. Phys. Lett. 2016, 658, 1-6.

(25) Goldmann, M.; javier Miguel-Sánchez,; West, A. H. C.; Yoder, B. L.; Signorell, R. 
Elrctron mean free path from angle-dependent photoelectron spectroscopy of aerosol particles. J. Chem. Phys. 2015, 142, 224304.

(26) Jacobs, M. I.; Kostko, O.; Ahmend, M.; Wilson, K. R. Low energy electron attenuation lengths in core-shell nanoparticles. Phys. Chem. Chem. Phys. 2017, 19, 13372-13378.

(27) Knelman, F.; Dombrowski, N.; Newitt, D. M. Calculations of electron inelastic mean free paths. III. Data for 15 inorganic compounds over the 50-2000 eV range. Surface and Interface Analysis 1991, 17, 1145.

(28) Wagner, C. D.; Davis, L. E.; Riggs, W. M. The Energy dependence of the electron mean free path. Surface and Interface Analysis 1980, 2, 53-55.

(29) Seidel, R.; Pohl, M. N.; Ali, H.; Aziz, E. F. Advances in liquid phase soft-x-ray photoemission spectroscopy: A new experimental setup at BESSY II. Review of Scientific Instruments 2017, 88, 073107.

(30) Kachel, T. The plane grating monochromator beamline U49/2 PGM1 at BESSY II. Journal of large-scale research facilities 2016, 2, A72.

(31) Timko, M. T.; Yu, Z.; Kroll, J.; Jayne, J. T.; Worsnop, D. R.; Miake-Lye, R. C.; Onasch, T. B.; Liscinsky, D.; Kirchstetter, T. W.; Destaillats, H. et al. Sampling artifacts from conductive silicone tubing. Aerosol Science and Technology 2009, 43, 855865.

(32) Papagiannouli, I.; Patanen, M.; Bozek, V. B. J. D.; de Anda Villa, M.; Huttula, M.; Kokkonen, E.; Lamour, E.; Mevel, E.; Pelimanni, E.; Scalabre, A. et al. Depth Profiling of the Chemical Composition of Free-Standing Carbon Dots Using X-ray Photoelectron Spectroscopy. The Journal of Physical Chemistry C 2018, 122, 14889-14897.

(33) Cochran, R. E.; Jayarathne, T.; Stone, E. A.; Grassian, V. H. Selectivity across the 
interface: A test of surface activity in the composition of organic-enriched aerosols from bubble bursting. J. Phys. Chem. Lett. 2016, 7, 1692-1696.

(34) Salter, M. E.; Hamacher-Barth, E.; Leck, C.; Werner, J.; Johnson, C. M.; Riipinen, I.; Nilsson, E. D.; Zieger, P. Calcium enrichment in sea spray aerosol particles. Geophys. Res. Lett. 2016, 43, 8277-8285.

(35) Yeh, J.; Lindau, I. Atomic subshell photoionization cross sections and asymmetry parameters : $1 \leq Z \leq 103$. Atomic Data and Nuclear Data Tables 1985, 32, 1 - 155 .

(36) Yeh, J. Atomic calculation of photoionization cross-sections and asymmetry parameters; Gordon and Breach Science Publishers: Gordon and Breach, Langhorne PA, 1993.

(37) Tang, C. Y.; Huang, Z.; Allen, H. C. Interfacial Water Structure and Effects of $\mathrm{Mg}^{2+}$ and $\mathrm{Ca}^{2+}$ Binding to the COOH Headgroup of a Palmitic Acid Monolayer Studied by Sum Frequency Spectroscopy. The Journal of Physical Chemistry B 2011, 115, 34-40.

(38) Cohen-Adad, R.; Counioux, J.-J.; Ferriol, M.; Adad, M.-T. S.-C.; Tenu, R.; Vallée, P.; Mioduski, T.; Szafranski, A. M.; Lorimer, J. W.; Russer, B. et al. Alkali metal and ammonium chlorides in water and heavy water (binary systems); Pergamon Press: Pergamon Press Inc., Maxwell House, Fairview Park, Elmsford, New York 10523, U S.A., 1991.

(39) Lide, D. R. CRC handbook of chemistry and physics, Internet Version; CRC Press: CRC Press, Boca Raton, FL, 2005.

(40) Liu, Y.; Yang, Z.; Desyaterik, Y.; Gassman, P. L.; Wang, H.; Laskin, A. Hygroscopic behavior of substrate-deposited particles studied by micro-FT-IR spectroscopy and complementary methods of particle analysis. Environ. Sci. Technol. 2008, 80, 633-642.

(41) Eom, H.-J.; Gupta, D.; Li, X.; Jung, H.-J.; Kim, H.; Ro, C. Influence of Collecting 
Substrates on the Characterization of Hygroscopic Properties of Inorganic Aerosol Particles. Analytical Chemistry 2014, 86, 2648-2656. 


\section{TOC Graphic}

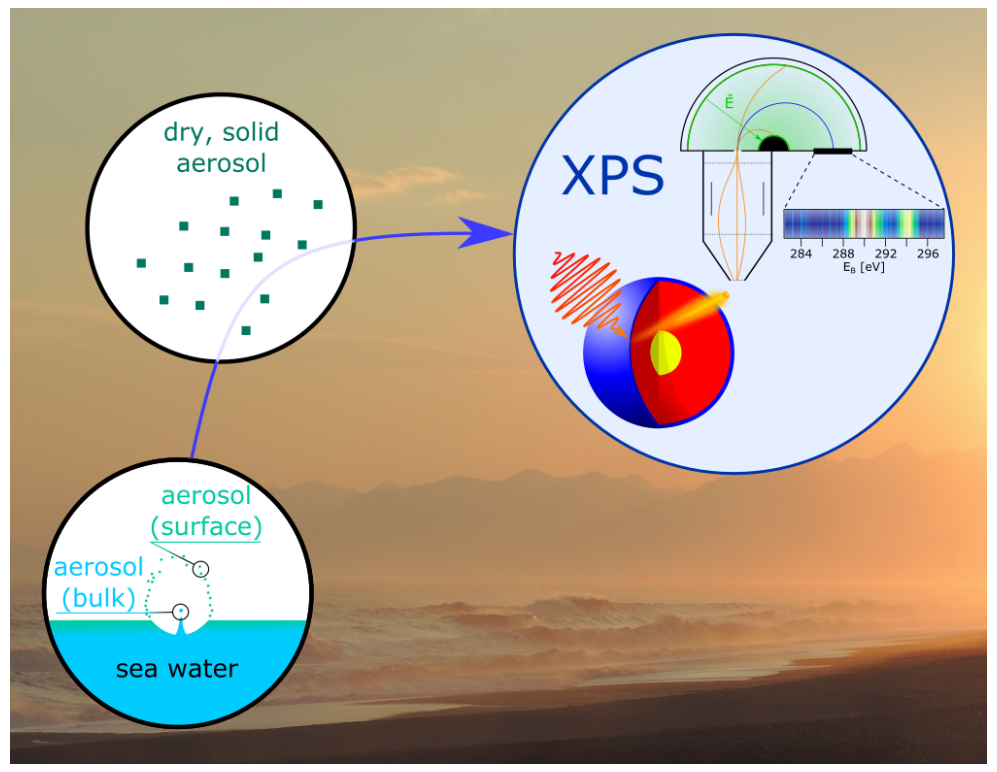




\title{
Supporting Information:
}

\section{The Influence of Organic Acids on the Surface Composition of Sea Spray Aerosol}

\author{
Isaak Unger, ${ }^{*, \dagger}$ Clara-Magdalena Saak, ${ }^{\dagger}$ Matthew Salter, ${ }^{\ddagger}, \boldsymbol{\Phi}, \dagger$ Paul Zieger,,,$+ \uparrow$ \\ Minna Patanen, ${ }^{*, \S}$ and Olle Björneholm ${ }^{\dagger}$ \\ †Uppsala University, Box 516, SE-75120 Uppsala, Sweden \\ $\ddagger$ Department of Environmental Science and Analytical Chemistry, Stockholm University, \\ SE-10691 Stockholm, Sweden \\ \Bolin Centre for Climate Research, SE-10691 Stockholm, Sweden \\ $\S$ Nano and Molecular Systems research Unit, Faculty of Science, P.O.Box 3000, FI-90014 \\ University of Oulu, Finland \\ E-mail: isaak.unger@physics.uu.se; Minna.Patanen@oulu.fi
}

Phone: (+358) 294481326 


\section{Composition of the $35 \mathrm{~g} / \mathrm{l}$ sea salt solution}

We used a $35 \mathrm{~g} / 1$ sea salt solution with inorganic sea salts provided by Sigma Aldrich. Based on the specification sheet provided by the supplier the following table gives the ion concentrations in this solution.

Table S1: Ion concentration in a $35 \mathrm{~g} / \mathrm{l}$ sea salt solution. Concentrations calculated based on the specification sheet.

\begin{tabular}{|c|c|}
\hline Ion & Concentration $[\mathrm{g} / \mathrm{l}]$ \\
\hline Chloride & $17.5-18.421$ \\
Sodium & $9.855-10.132$ \\
Sulfate & 2.45 \\
Potassium & $0.276-0.368$ \\
Calcium & 0.368 \\
Carbonate & $0.129-0.184$ \\
Boron & 0.005 \\
Magnesium & 1.216 \\
Strontium & 0.008 \\
\hline
\end{tabular}

\section{Quantitative analysis of signal intensities}

We describe in the following how we obtained the enrichment $(R)$ of a given ionic species with respect to chloride. We consider $\mathrm{Cl}^{-}$to be always present in the surface region to a similar degree regardless of the composition of the parent solution due to its abundance. We fitted the respective spectra with Voigt profiles and obtained the peak area $\left(A_{X} ; X\right.$ signifying the respective ionic species). The areas had to be normalized to unit photon flux measured by the current in a photo-diode $\left(I_{X}\right)$, unit photoionization cross section $\left(\sigma_{X}\right)^{1-3}$ and unit molarity in the parent solution $\left(n_{X}\right)$.

$$
R=\frac{A_{X}}{A_{C l 2 p}} \cdot\left(\frac{\sigma_{X} I_{X} n_{X}}{\sigma_{C l 2 p} I_{C l 2 p} n_{C l 2 p}}\right)^{-1}
$$

We neglected the impact of the photoelectron angular distribution in our analysis.

The result of this analysis for the sodium enrichment as a function of the concentration of 


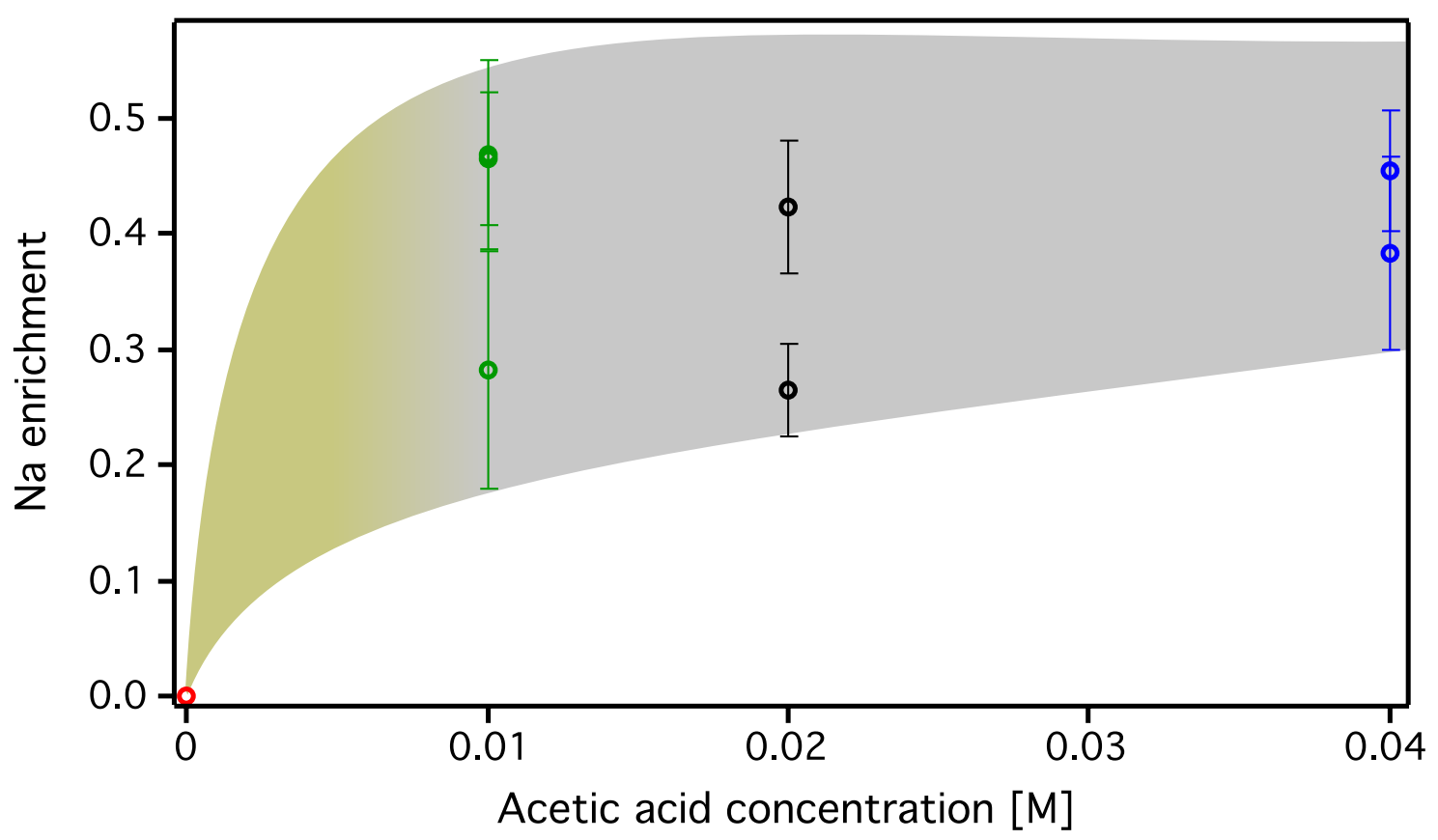

Figure S1: The graph shows the surface enrichment of $\mathrm{Na}^{+}$relative to $\mathrm{Cl}^{-}$in dry aerosol particles as a function of the acetic acid concentration in the parent solution. The enrichment factors have been derived from fitting XP spectra; the gray area is meant to guide the eye and signifies the expected range of the error bars. If the $\mathrm{Na}^{+}$surface concentration is related in any way to the concentration of acetic acid in the parent solution, then, apparently, changes take place below $0.01 \mathrm{M}$ acetic acid. 
acetic acid in the parent solution is shown in figure S1. The first data point at $0 \%$ organic concentration is $1 \mathrm{M}$ sea salt $+0.02 \mathrm{M} \mathrm{CaCl}_{2}$ solution (Figure 2 (c) in the main article). Compared to that point, sodium is enriched on the particle surface as the acid is added to the solution, but its amount still remains lower than expected based on the concentration of the bulk solution (enrichment factor is less than 1). It appears that the sodium enrichment does not vary much with the acetic acid concentration in our data. All significant changes in the $\mathrm{Na}^{+}$surface enrichment must happen when the concentration of acetic acid is below $0.01 \mathrm{M}$.

The majority of the uncertainty in the results we present is due to uncertainty in the peak fitting procedure. To obtain a good estimate of the fit error, the fit parameters have been varied until the fit did not agree with the data. This range in the fit parameters translates into an error for the obtained peak area.

\section{Structure of dried sea spray aerosol}

We interpret our data such that the main driving forces for the abundance of either Ca or $\mathrm{Na}$ at the particle surface are the efflorescence points of salts and their concentration in the parent solution (and thus in the aqueous droplets produced from the solution). Depending on the composition of the parent solution, this gives rise to particle structures we sketch in figure S2. Note that we infer these structures indirectly and solely based on our surface sensitive measurements. Other ions present in the sea salt mixture but not detected in our experiment may also form various salts to the core of the particles, but discussion here is restricted to the observed ions and formed salts supported by the literature. These images only serve to illustrate our interpretation of the data.

In a binary solution of $\mathrm{NaCl}$ and $\mathrm{CaCl}_{2}$, only $\mathrm{NaCl}$ can be detected on the surface of the particles. Figure S2a) depicts the struture of dry aerosol particles originating from this solution. They have $\mathrm{CaCl}_{2}$ core and a $\mathrm{NaCl}$ shell.

Artificial sea salt solution contains a variety of salts (see table S1) and we limit our discussion 

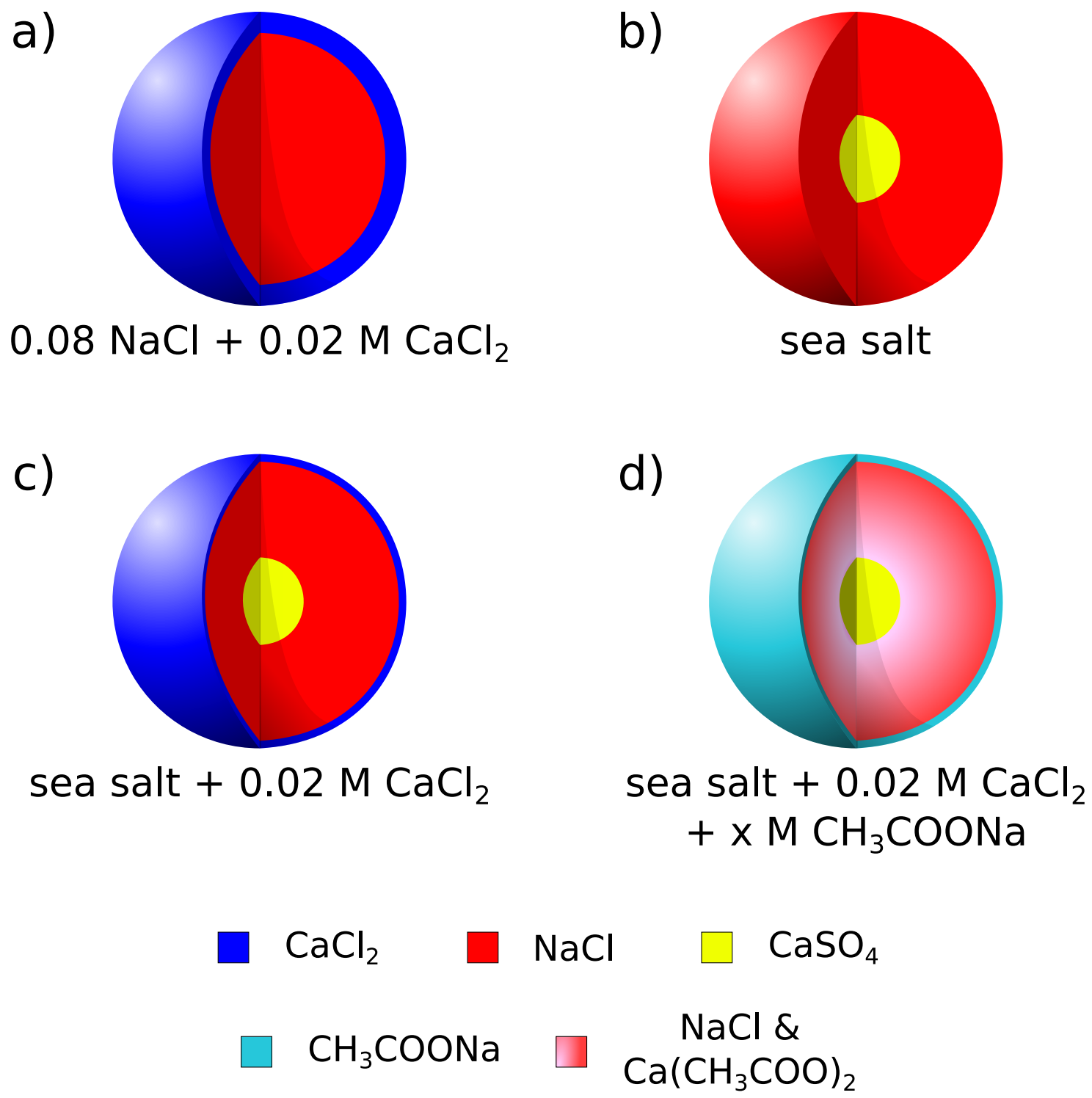

Figure S2: This figure sketches the structure of dried sea spray aerosol originating from various parent solutions we suggest within the paper.

to a few of them. Figure S2b) shows the sketches the structure of dry particles originating from a sea salt solution. At decreasing relative humidity, a core of calcium sulfate salts crystallizes first and is surrounded by a shell containing mostly $\mathrm{NaCl}$.

We conducted experiments on aerosol from a sea salt solution, which had been enriched with additional $\mathrm{CaCl}_{2}$ (sketch of the structure in figure S2c)). The inner two shells of these particles should be similar to the ones originating from a pure sea salt solution, here, however an outer shell of $\mathrm{CaCl}_{2}$ forms around the $\mathrm{NaCl}$ shell. The reason for the formation of a second 
shell is the excess $\mathrm{Ca}^{2+}(\mathrm{aq})$ left over after the formation of the $\mathrm{CaSO}_{4}$-containing core.

Finally, in figure S2d), we suggest the structure of aerosol particles from parent solutions, which contain sea salts, additional $\mathrm{CaCl}_{2}$ and acetic acid. After the initial formation of a $\mathrm{CaSO}_{4}$-containing core, a first shell forms. Since we only have data about the solubilities of the involved salts at our disposal, we cannot tell for sure whether this shell contains a mixture of $\mathrm{NaCl}$ and sodium acetate or whether two separate shells form. The solubilities of $\mathrm{NaCl}$ and sodium acetate are very similar. The topmost layer of such particles certainly contains acetate, sodium and chloride. 


\section{References}

(1) Thompson, A.; Attwood, D.; Gullikson, E.; Howells, M.; Kim, K.-J.; Kirz, J.; Kortright, J.; Lindau, I.; Liu, Y.; Pianetta, P. et al. X-ray data booklet; Lawrence Berkeley National Laboratory: University of California, Berkeley, CA 94720, 2009.

(2) Yeh, J.; Lindau, I. Atomic subshell photoionization cross sections and asymmetry parameters : $1 \leq Z \leq 103$. Atomic Data and Nuclear Data Tables 1985, 32, 1 - 155 .

(3) Yeh, J. Atomic calculation of photoionization cross-sections and asymmetry parameters; Gordon and Breach Science Publishers: Gordon and Breach, Langhorne PA, 1993. 